\title{
The Effects of Ovine Whey Powders on Durum Wheat-Based Doughs
}

\author{
Nicola Secchi, ${ }^{1,2}$ Costantino Fadda $\left(\mathbb{D},{ }^{2}\right.$ Massimo Piccinini, ${ }^{3}$ Ivo Pinna, \\ Antonio Piga, ${ }^{2}$ Pasquale Catzeddu, ${ }^{1}$ and Simonetta Fois ${ }^{1}$ \\ ${ }^{1}$ Porto Conte Ricerche Srl, Località Tramariglio, 07041 Alghero, Italy \\ ${ }^{2}$ Dipartimento di Agraria, Università degli Studi di Sassari, Viale Italia 39/A, 07100 Sassari, Italy \\ ${ }^{3}$ ENEA Centro Ricerche, Via E. Fermi 45, 00044 Frascati, Italy \\ Correspondence should be addressed to Costantino Fadda; cfadda@uniss.it
}

Received 26 October 2017; Accepted 11 January 2018; Published 13 February 2018

Academic Editor: Hüseyin Erten

Copyright (C) 2018 Nicola Secchi et al. This is an open access article distributed under the Creative Commons Attribution License, which permits unrestricted use, distribution, and reproduction in any medium, provided the original work is properly cited.

\begin{abstract}
Two types of ovine whey powder, with different protein content, were added at increasing substitution rates to two types of semolina, one with strong and tenacious gluten and the other with weak and sticky gluten. For each dough the optimum mixing time and hydration level were calculated using the consistograph. The whey powder negatively affected the leavening volume of all doughs, at all percentages except the lowest one (5\%), mainly because of its effects on the elastic component of gluten as measured with a stress relaxation test. Differences of the secondary structure of gluten proteins among samples were investigated by analyzing the amide I band in the Fourier transform infrared spectra of the dough. Weak and strong semolina showed a different relative percentage of $\alpha$-helix, random coil, and $\beta$-sheet structures. The longer mixing times for dough formation when using semolina with strong gluten led to an increase in $\alpha$-helices and random coils, which caused a worse leavening performance than the weak-gluten semolina.
\end{abstract}

\section{Introduction}

Semolina from durum wheat is used to make different types of local breads in the Mediterranean area, particularly in Southern Italy [1]. The chemical and rheological characteristics of semolina greatly affect the handling properties of the dough, its leavening capacity, and the final quality of the bread. Semolina characterized by a strong gluten network, resulting in high gluten index and $P$ to $L$ values, is suitable for producing soft bread with low specific weight [2] due to the high leavening and gas retention capacity. In contrast, semolina with a weak-gluten network results in dough that is not able to expand well, thus producing bread that is heavy and hard with an inhomogeneous structure [3].

In recent years, an increasing consumer desire for high food quality has led to renewed interest in ancient raw materials and traditional food production [4]. The importance of this topic was stated at the Universal Exhibition hosted in Milan in 2015 [5] where "the best of the agri-food and gastronomic traditions of each of the exhibitor countries" were presented. In this context, local landraces and old wheat varieties have recently been rediscovered, and there has been a general effort to reintroduce them into the bakery industry. However, the replacement process has been hindered by their poor agronomic characteristics and poor gluten quality, which renders them unsuitable for bread making in modern bakery plants.

The functional properties of dough can be improved by the addition of additives as whey powder, which is commonly used as a food fortifier or as a source of low-cost proteins [6]. Whey lactose and proteins can be added to obtain food texture modifications (gelling, film-forming, foaming, and emulsifying) $[7,8]$. Whey proteins also have important nutritional and biological functions, since the protein components and their peptide fragments are bioactive; for example, they exert antimicrobial and antiviral actions as well as anticarcinogenic activity and they have the capacity to modulate the innate immune system [9]. Moreover, 1 million tons of ovine whey is produced annually in Southern Italy [10], resulting in a number of environmental problems that include 
pollution. Currently, the conversion of by-products from the dairy industry into dry products is one of the main industrial conversion processes. A number of scientific papers have investigated the use of whey powders derived from bovine milk, whereas fewer scientific reports are available on ovine whey powder [11].

The purpose of this study was to investigate the effect of adding ovine whey powder (OWP) in semolina-based doughs. Two types of low-grade semolina were used to prepare the doughs: one derived from a blend of strong durum wheat cultivars; the other was obtained from Senatore Cappelli cultivar, an old and tall durum wheat genotype, characterized by weak and sticky gluten, that poorly fits with the technological requirements of modern industrial plants. The effects of increasing substitution rates of OWP on the two types of dough were investigated. The physicalchemical properties and rheological behaviour of the doughs were evaluated and leavening trials were conducted. Potential molecular modifications in gluten conformation caused by the addition of OWP were investigated using Fourier transform infrared (FT-IR) spectroscopy.

\section{Materials and Methods}

2.1. Raw Materials, Dough Preparation, and Analyses. Two types of commercial low-grade semolina were purchased from a local mill (Molino Galleu, Sardinia, Italy). The first, referred to as $4 \mathrm{~T}$, was obtained by milling the Senatore Cappelli cultivar, and the other, referred to as $48 \mathrm{~T}$, derived from a blend of durum wheat cultivars that are commonly used to make pasta and semolina-based breads. Two types of commercial OWP (Alimenta Srl, Sardinia, Italy), referred to as $\mathrm{A}$ and $\mathrm{B}$, were added to the dough formulations at different substitution rates $(0,5,10$, and $15 \% \mathrm{w} / \mathrm{w})$. Hereafter, dough samples will be denoted by the type of semolina ( $4 \mathrm{~T}$ or $48 \mathrm{~T}$ ) and the OWP type (A or B) followed by the relative percentage (e.g., 4TA10 means semolina $4 \mathrm{~T}$ added with OWP $\mathrm{A}$ at the percentage of $10 \%)$. Moisture (\%), ash (\%), and protein content (\%) calculated on a dry basis (d.b.), gluten index (\%), and dry gluten content (\% d.b.) were measured on semolina following the AACC Approved Methods 44-15A, 08-12, 46-12, 66-20, 38-12A, and 54-30A, respectively [12]. The latter method was adapted to durum wheat according to Dubois et al. [13]. The Alveo-Consistograph (Chopin Technologies, France) was used to determine water adsorption capacity at a consistency of 2,200 mbar (fixed moisture basis of 15\%), the pressure drop after $450 \mathrm{~s}$ of mixing (D450, mbar), and the time to reach the target consistency of 2,200 mbar (TPrMAX), according to the AACC Approved Method 54-50 [12]. The dough was prepared in the consistograph mixer bowl at a fixed temperature $\left(24^{\circ} \mathrm{C}\right)$ and at adapted hydration. OWP at different percentages, semolina, and yeast $(1 \% \mathrm{w} / \mathrm{w}$, total weight of semolina plus OWP A or OWP B) were mixed in the consistograph mixing bowl for $2 \mathrm{~min}$ before then addition of $2.5 \%$ saline solution. The mixing process was interrupted when the value of the dough consistency was $75 \%$ of the maximum pressure, after having exceeded the maximum pressure $(2,200 \pm 7 \% \mathrm{mbar})$ (Figure 1), as for Vinci et al. [14].

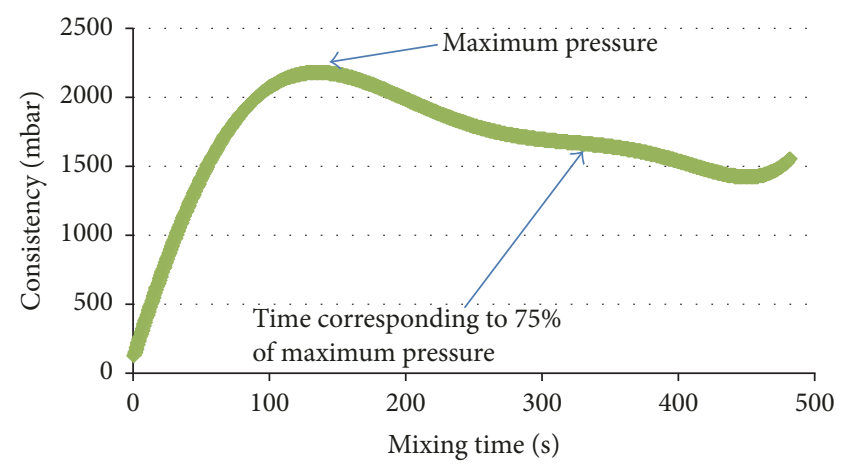

FIGURE 1: Curve from the consistograph: dough consistency versus mixing time. The mixing time chosen in this work is indicated.

After mixing, the dough was sheeted and formed for alveographic analysis. Another dough was prepared for each treatment, and when the desired consistency was reached, it was extruded, sheeted, and divided into five pieces that were used for a stress relaxation test with a texture analyzer. A third dough for each treatment was prepared in the same way in triplicate and used for the leavening trial.

2.2. Stress Relaxation Test. The TA.XT2i Texture Analyser (Stable Micro Systems Ltd., Surrey, UK) equipped with a $30 \mathrm{~kg}$ load cell and a P50 probe was used for the stress relaxation test on the dough [15] and force $(\mathrm{N})$ versus time (s) curves were recorded using Texture Expert Exceed software, version 2.64. The test speed was $1 \mathrm{~mm} \mathrm{~s}^{-1}$. The instantaneous strain applied to the dough was $10 \%$, and the resulting stress was recorded for $40 \mathrm{~s}$. A generalized Maxwell model was used to fit the stress relaxation data in accordance with Campus et al. [16], as follows:

$$
\sigma(t)=\sum_{i=1}^{n} C_{i}\left(e^{-\left(t / \tau_{i}\right)}\right)+\sigma_{e},
$$

where $\sigma$ is the stress $(\mathrm{N})$ at a given time, $t(\mathrm{~s}), C_{i}$ is the stress relaxation constant $(\mathrm{N}), \sigma_{e}$ is the equilibrium stress $(\mathrm{N})$, and $\tau_{i}$ (s) are the relaxation times of the Maxwell elements. TableCurve 2D version 5.01 (Systat Software Inc., San Jose, CA, USA) was used to perform regression analyses on the stress relaxation data using the Levenberg-Marquardt method. $R^{2}$ (i.e., the percentage of explained variation) and maximum relative difference (MRD) were used to evaluate the goodness of fit. Only the relaxation part of the curve was used for the fitting procedure. A model with three Maxwell elements $(n=3)$ was optimal to describe the viscoelastic behaviour of the dough $\left(R^{2} \leq 0.98\right.$ and $\left.\mathrm{MRD} \leq 7\right)$. The maximum force achieved in the stress relaxation test was $3.8 \pm 0.3$, and it was the same in all the doughs, confirming that homogeneous dough was obtained in terms of consistency.

2.3. Leavening Trial. Leavening tests were performed as described by Vinci et al. [14]. For each treatment, the dough was prepared in the consistograph mixing bowl, as described in Section 2.1. After the preparation of the dough, $100 \mathrm{~g}$ was 
TABle 1: Properties of low-grade semolina (4T, 48T) and ovine whey powders (A, B).

\begin{tabular}{|c|c|c|c|c|c|c|c|c|}
\hline Batch & $\begin{array}{c}\text { Ashes } \\
\left(\% \text { d.b. }{ }^{*}\right)\end{array}$ & $\begin{array}{c}\text { Protein content } \\
(\% \text { d.b. })\end{array}$ & $\begin{array}{c}\text { Moisture } \\
(\%)\end{array}$ & $\begin{array}{c}\text { Gluten index } \\
(\%)\end{array}$ & $\begin{array}{c}P^{* *} \\
(\mathrm{~mm})\end{array}$ & $\begin{array}{c}L^{* *} \\
(\mathrm{~mm})\end{array}$ & $\begin{array}{c}W^{* *} \\
\left(\mathrm{~J} * 10^{-4}\right)\end{array}$ & $P / L^{* *}$ \\
\hline $4 \mathrm{~T}$ & $1.02 \pm 0.02$ & $11.1 \pm 0.09$ & $15.4 \pm 0.10$ & $56.0 \pm 0.01$ & $59.9 \pm 1.8$ & $49.0 \pm 6.9$ & $91.9 \pm 6.4$ & $1.24 \pm 0.20$ \\
\hline $48 \mathrm{~T}$ & $1.03 \pm 0.02$ & $12.9 \pm 0.48$ & $15.2 \pm 0.05$ & $92.2 \pm 0.02$ & $98.2 \pm 2.1$ & $45.8 \pm 5.7$ & $173.7 \pm 8.9$ & $2.18 \pm 0.29$ \\
\hline A & $8.50 \pm 0.05$ & $15.1 \pm 0.15$ & $4.1 \pm 0.12$ & - & - & - & - & - \\
\hline B & $6.00 \pm 0.04$ & $35.2 \pm 0.18$ & $4.2 \pm 0.08$ & - & - & - & - & - \\
\hline
\end{tabular}

${ }^{*}$ Dry basis. ${ }^{* *}$ Alveograph parameters at constant hydration: $P$, maximum overpressure; $L$, index of swelling; $W$, deformation energy; $P / L$, configuration ratio. Data were expressed as mean \pm standard deviation.

transferred to graduated glass cylinders $(250 \mathrm{~mL}$ capacity and $15 \mathrm{~mm}$ diameter) and left at $25^{\circ} \mathrm{C}$ until maximum leavening volume was attained. The increase in the height of the dough was recorded every $15 \mathrm{~min}$.

2.4. FT-IR Spectroscopy. FT-IR spectral measurements were performed under vacuum conditions using the Bruker infrared Vertex 70 interferometer (Bruker Optik, Ettlingen, Germany) equipped with a deuterated triglycine sulfate detector, and spectral data were processed using Bruker OPUS 6.5 software. The dough samples were freeze-dried before FT-IR analysis to avoid interference from water [17]. After freeze drying, each dough sample was homogenized using an agate mortar and pestle, after which an aliquot of $3 \mathrm{mg}$ was mixed with $297 \mathrm{mg}$ anhydrous potassium bromide (KBr, >99\%; Sigma-Aldrich, St. Louis, MO, USA) and pelleted for the analyses. The spectra were recorded in the $400-4000 \mathrm{~cm}^{-1}$ range by averaging 128 scans at a resolution of $4 \mathrm{~cm}^{-1}$. The background was evaluated by measuring the $\mathrm{KBr}$ signals. Three replicates were measured for each treatment. The amide I band was studied in the spectral range from 1710 to $1580 \mathrm{~cm}^{-1}$. After normalization, A and B spectra were subtracted from the spectrum for the dough, after being multiplied by their relative percentage in the dough. The peak positions, corresponding to the secondary structure of the proteins, were identified using the second derivative spectra and used to initialize the best fit of the amide I band in the abovementioned spectral range. The best fit was obtained using the mixed Gaussian-Lorentzian function. The percentages of integrated peak areas were then calculated and referred to the secondary structure of protein, following the assignments of Wang et al. [18].

2.5. Statistical Analysis. Principal component analysis (PCA) was performed on the correlation matrix of the variables related to semolina and dough properties, mixing parameters, and volume of leavening. The component loadings were calculated as simple correlations (using Pearson's $r$ ) between the components (i.e., the component scores for each dough) and the original variables. Data related to properties of dough (mixing time, volume of leavening, and protein content) were analyzed by one-way analysis of variance (ANOVA). When appropriate, mean separation was performed according to Duncan's multiple range test at $p \leq 0.05$.

\section{Results and Discussion}

3.1. Characteristics of Semolina and OWP. The chemical and physical properties of the two types of semolina and OWPs are shown in Table 1. The data show the differences between the two semolina samples with regard to protein content, gluten index, and the alveograph parameters configuration ratio $(P / L)$ and deformation energy $(W)$. 48T had a higher protein content, gluten tenacity, and extensibility than $4 \mathrm{~T}$; the latter was obtained from a wheat cultivar that is well known for its poor gluten quality, due to the pattern of the high molecular weight glutenin subunit 20 (HMW-GS 20), which is the predominant pattern in durum wheat landraces and old genotypes [19]; however, in new cultivars, as those of 48T, it has been almost completely replaced by the $6+8$ and $7+8$ HMW patterns, which exhibit stronger dough properties and superior baking quality than HMW-GS 20 cultivars.

There were differences in the chemical composition of the two OWPs, with B having a higher protein content and lower ash content than A (Table 1).

3.2. Effect of OWPs on Rheological and Leavening Properties of the Dough. Rheological, physical, and chemical data, collected from $4 \mathrm{~T}$ and $48 \mathrm{~T}$ doughs supplemented with OWP, were correlated and processed using PCA. The results of the PCA analysis are reported in Figure 2 and Table 2. The first two PC axes explained $85.3 \%$ of the differences among samples (Figure 2). Almost all of the variables contributed, both positively and negatively, to the first axes, whereas the original variable that contributed most to the second axis was the relaxation time of the Maxwell model $\tau_{i}$. The position of the samples with respect to the first PC axis was consistent with the addition of whey proteins, which moved the samples to the negative part of the first principal component (PC1). The negative association between PC1 and the protein content of the dough $(r=-0.90)$, and the positive association between $\mathrm{PCl}$ and the volume of leavening $(r=0.92)$, highlights the negative effect of whey addition on the leavening volume of semolina (Table 2). Commonly the leavening capacity is positively related to the protein content of the dough [20]; however, in this case, although the addition of whey increased the protein content, it also greatly strengthened the dough and probably led to greater resistance to extension. The correlations among the original variables confirmed this hypothesis, as strong 


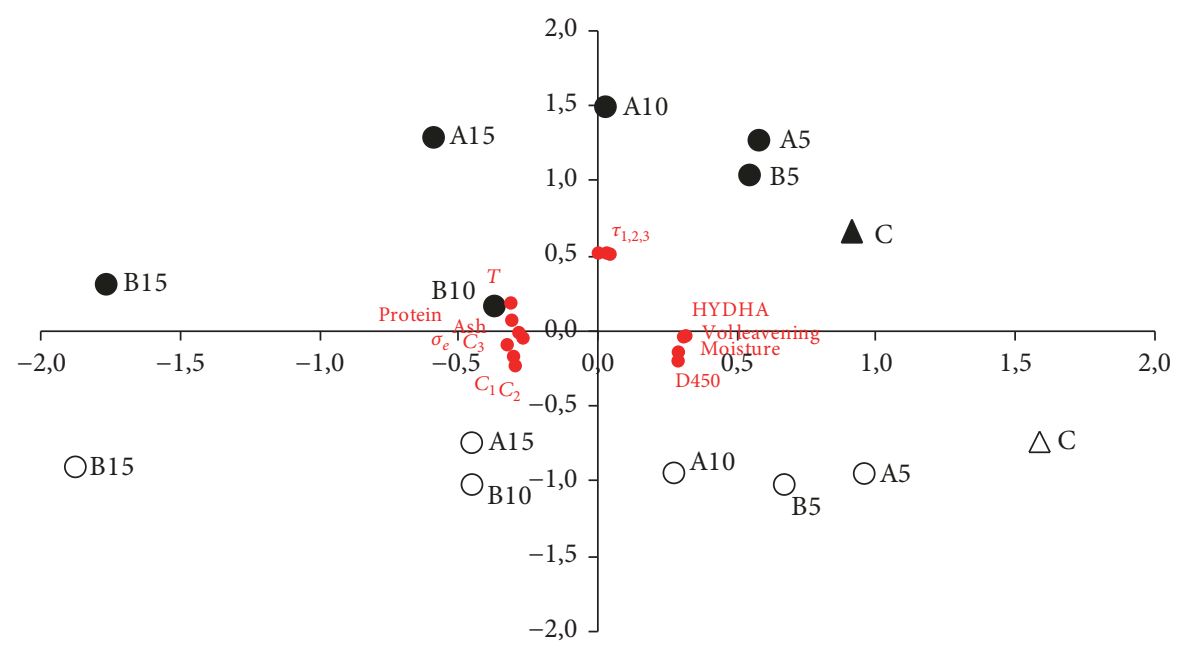

FIGURE 2: Principal component analysis (based on the correlation matrix) of the dough samples. Biplot of factor scores (points). 4T control $(\triangle)$; 48T control $(\mathbf{\Delta})$; 4T dough with ovine whey powder $(\mathrm{A}, \mathrm{B})(\mathrm{O})$; 48T dough with ovine whey powder (A, B) (black circle); loadings (red circle). Stress relaxation test parameters: $C_{1}, C_{2}$, and $C_{3}$ : decay force of the Maxwell model; $\tau_{1}$, $\tau_{2}$, and $\tau_{3}$ : relaxation times of the Maxwell model; $\sigma_{e}$ : the residual modulus that remained unrelaxed. Alveograph parameters at adapted hydration: T: maximum overpressure (mm). Consistograph parameters: HYDHA: actual hydration of dough used in the test (15\% mb); D450 dough weakness at $450 \mathrm{~s}$. Vol leavening: leavening volume $(\mathrm{mL})$.

TABLE 2: Proportion of total variation and eigenvectors of principal component (PC) axes in a principal component analysis performed on all the traits measured.

\begin{tabular}{lcccc}
\hline & \multicolumn{2}{c}{ Eigenvectors } & \multicolumn{2}{c}{ Loadings } \\
& Axis $1^{*}$ & Axis $2^{* *}$ & Axis 1 & Axis 2 \\
\hline Moisture & 0.29 & -0.14 & 0.84 & -0.25 \\
Ash & -0.29 & -0.01 & -0.83 & -0.01 \\
Protein & -0.31 & 0.08 & -0.90 & 0.14 \\
HYDHA & 0.31 & -0.03 & 0.89 & -0.06 \\
D450 & 0.29 & -0.19 & 0.84 & -0.36 \\
$T$ & -0.31 & 0.19 & -0.91 & 0.36 \\
Vol leavening & 0.32 & -0.03 & 0.92 & -0.05 \\
$C_{1}$ & -0.30 & -0.16 & -0.89 & -0.30 \\
$\tau_{1}$ & 0.04 & 0.52 & 0.12 & 0.96 \\
$C_{2}$ & -0.30 & -0.23 & -0.87 & -0.42 \\
$\tau_{2}$ & 0.03 & 0.52 & 0.10 & 0.98 \\
$C_{3}$ & -0.33 & -0.09 & -0.95 & -0.16 \\
$\tau_{3}$ & 0.00 & 0.52 & 0.01 & 0.98 \\
$\sigma_{e}$ & -0.27 & -0.04 & -0.78 & -0.08 \\
\hline
\end{tabular}

Component loadings are the simple correlations between the principal components and the original variables. * Proportion of total variation is $60.3 \%$.

${ }^{* *}$ Proportion of total variation is $25.0 \%$. Stress relaxation test parameters: $C_{1}, C_{2}$, and $C_{3}$, decay force of Maxwell model; $\tau_{1}, \tau_{2}$, and $\tau_{3}$, relaxation times of the Maxwell model; $\sigma_{e}$, the residual modulus that remained unrelaxed. Alveograph parameter at adapted hydration: $T$, maximum overpressure. Consistograph parameters: HYDHA, actual hydration of dough used in the test; D450, dough weakness at $450 \mathrm{sec}$. Vol leavening, leavening volume.

associations among protein content and all of the indices of elasticity and strength of the dough (i.e., alveographic tenacity of the dough $T$, Maxwell decay force $C_{i}$, and equilibrium stress $\sigma_{e}$ ) were found. The strong correlations between the variables and $\mathrm{PCl}$ established a strong relationship among them, notably between the leavening capacity of the dough and the consistograph parameters. Here, data from the consistograph (Table 3) show that increasing amounts of OWP lead to reduced water adsorption of the dough (HYDHA), in agreement with other authors $[21,22]$. Note that the available literature refers to flour from Triticum aestivum L., and no data have been published to date on the effects of the addition of whey protein to semolina-based dough. The effect of OWP on the dough was revealed by the higher TPrMAX and mixing time values (Table 3 ) and the concomitant lowering of D450 values (Table 3), which indicated an increase of dough strength and dough stability as the OWP percentage increased, similarly to the findings reported by Madenci and Bilgiçli [23].

In a previous study [14], we highlighted the key role of the technological parameters (i.e., hydration level of the dough and mixing time) in influencing the leavening volume of a semolina-based dough. We suggested that the optimum mixing time approximately corresponded to the time required to reduce the maximum pressure to $75 \%$ of its value (Figure 1 ), which resulted in a softer and more elastic dough that was better suited to leavening. This procedure was applied in the current study to make sure that all dough samples were mixed until the best consistency for leavening was attained, which explains why the mixing times were extremely variable among the samples, ranging from $330 \mathrm{~s}$ to $1,065 \mathrm{~s}$ (Table 3). As expected, the shortest mixing time was in the 4TC. The dough made from the stronger $48 \mathrm{~T}$ showed a longer mixing time than the dough made from $4 \mathrm{~T}$ in all treatments. We generally observed that the addition of OWP led to an increase in mixing time, consistent with the degree of substitution of semolina with OWP (Table 3). The leavening volume of 4TC was higher than that of the $48 \mathrm{~T}$ samples (Table 3), although $4 \mathrm{TC}$ had a lower protein content and a poorer gluten quality, 
TABLE 3: Properties of dough samples. TPrMax, HYDHA, mixing time, and D450 are Consistograph parameters.

\begin{tabular}{|c|c|c|c|c|c|c|}
\hline Samples & $\begin{array}{l}\text { TPrMAX } \\
\text { (s) }\end{array}$ & $\begin{array}{l}\text { HYDHA } \\
(\%)\end{array}$ & $\begin{array}{l}\text { Mixing time } \\
\text { (s) }\end{array}$ & $\begin{array}{l}\mathrm{D} 450 \\
(\mathrm{mb})\end{array}$ & $\begin{array}{l}\text { Volume leavening } \\
(\mathrm{mL})\end{array}$ & $\begin{array}{c}\text { Protein content } \\
(\%)\end{array}$ \\
\hline $4 \mathrm{TC}$ & $110.5^{\mathrm{g}}$ & $50.3^{\mathrm{a}}$ & $330^{\mathrm{g}}$ & $880^{\mathrm{a}}$ & $155^{\mathrm{a}}$ & $11.07^{1}$ \\
\hline 4TA5 & $147.5^{\mathrm{fg}}$ & $45.0^{\mathrm{cd}}$ & $480^{\mathrm{e}}$ & $528^{\mathrm{b}}$ & $165^{\mathrm{a}}$ & $11.65^{\mathrm{i}}$ \\
\hline 4TA10 & $234.5^{\mathrm{df}}$ & $39.9^{f}$ & $697^{\mathrm{d}}$ & $357^{\mathrm{c}}$ & $139^{\mathrm{b}}$ & $12.10^{\mathrm{hi}}$ \\
\hline 4TA15 & $325.0^{\mathrm{ad}}$ & $36.8^{\mathrm{g}}$ & $930^{\mathrm{b}}$ & $211^{\mathrm{ef}}$ & $115^{\mathrm{de}}$ & $12.72^{\mathrm{g}}$ \\
\hline 4TB5 & $150.5^{\mathrm{fg}}$ & $45.5^{\mathrm{c}}$ & $480^{\mathrm{e}}$ & $604^{\mathrm{b}}$ & $142^{\mathrm{b}}$ & $12.70^{\mathrm{g}}$ \\
\hline $4 \mathrm{~TB} 10$ & $243.0^{\mathrm{cf}}$ & $41.0^{\mathrm{e}}$ & $765^{c}$ & $364^{c}$ & $86^{\mathrm{f}}$ & $15.08^{\mathrm{cd}}$ \\
\hline $4 \mathrm{~TB} 15$ & $385.0^{\mathrm{ab}}$ & $35.9^{\mathrm{g}}$ & $892^{\mathrm{b}}$ & $119^{\mathrm{fg}}$ & $67^{\mathrm{g}}$ & $15.54^{\mathrm{b}}$ \\
\hline $48 \mathrm{TC}$ & $150.0^{\mathrm{fg}}$ & $48.5^{\mathrm{b}}$ & $420^{\mathrm{f}}$ & $585^{\mathrm{b}}$ & $135^{\mathrm{bc}}$ & $12.86^{\mathrm{g}}$ \\
\hline 48TA5 & $218.5^{\mathrm{ef}}$ & $44.2^{\mathrm{d}}$ & $682^{\mathrm{d}}$ & $327^{\mathrm{cd}}$ & $135^{\mathrm{bc}}$ & $12.53^{\mathrm{gh}}$ \\
\hline 48TA10 & $398.0^{\mathrm{a}}$ & $39.3^{\mathrm{f}}$ & $930^{\mathrm{b}}$ & $160^{\mathrm{eg}}$ & $125^{\mathrm{cd}}$ & $12.97^{\mathrm{fg}}$ \\
\hline 48TA15 & $381.5^{\mathrm{ab}}$ & $36.1^{\mathrm{g}}$ & $1050^{\mathrm{a}}$ & $82^{\mathrm{g}}$ & $115^{\mathrm{de}}$ & $13.72^{\text {de }}$ \\
\hline 48TB5 & $222.0^{\mathrm{ef}}$ & $44.7^{\mathrm{cd}}$ & $675^{\mathrm{d}}$ & $403^{c}$ & $119^{\mathrm{de}}$ & $13.43^{\mathrm{ef}}$ \\
\hline $48 \mathrm{~TB} 10$ & $283.5^{\text {be }}$ & $41.1^{\mathrm{e}}$ & $795^{c}$ & $236^{\mathrm{de}}$ & $90^{f}$ & $14.30^{c}$ \\
\hline 48TB15 & $341.0^{\mathrm{ac}}$ & $36.3^{g}$ & $1065^{\mathrm{a}}$ & $224^{\mathrm{e}}$ & $65^{\mathrm{g}}$ & $16.61^{\mathrm{a}}$ \\
\hline
\end{tabular}

Samples with different superscript letters within each column are significantly different at $p<0.05$ according to Duncan's multiple range test; TPrMax, time to reach the maximum pressure of 2,200 mbar; HYDHA, actual hydration of dough used in the test (15\% moisture basis); D450, pressure drop from PrMax to pressure after $450 \mathrm{~s}$.

in accordance with the conclusions of [14], showing that the technological parameters used during dough preparation influence the leavening performance more than the semolina characteristics. Generally, the addition of OWP had a negative effect on the leavening volume compared with the respective controls in both $4 \mathrm{~T}$ and $48 \mathrm{~T}$. This result is in accordance with most studies, which have demonstrated that almost every milk fraction, including whey proteins (powders or concentrates) and casein, depresses loaf volume [21, 24]. In our study, the depressing effect was greater in $4 \mathrm{~T}$ than $48 \mathrm{~T}$ at the highest OWP concentrations (i.e., A at $15 \%$ and B at 10\% and $15 \%$; Table 3). Conversely, at the lowest concentration of $\mathrm{A}(5 \%)$, dough made from $4 \mathrm{~T}$ and $48 \mathrm{~T}$ showed the same leavening volume as their respective controls. As far as the differences in OWP A and OWP B are concerned, data in Table 3 indicate that the leavening volume of doughs was lower when OWP B was used.

Our data show that the addition of OWP leads to increased dough elasticity, as determined by the contribution of the stress relaxation constant $C_{i}$ to PC1 (Figure 2). We observed that the greater the reduction of the leavening volume was, the higher the increase in $C_{i}$ values was; for example, in the dough made from $4 \mathrm{~T}$ and $48 \mathrm{~T}$ with $\mathrm{B}$ at a $15 \%$ substitution rate, the $C_{1}$ value increased by $151 \%$ and $81 \%$, respectively, with respect to their controls. At the same time, the leavening volume decreased by $56 \%$ and $52 \%$ in the same samples (data not shown). These data suggest that the addition of OWP resulted in a gluten matrix that had a greater resistance to extension, which negatively affected the volume of leavening. Fois et al. [19] reported that samples with a gluten network that is too strong and with a $P$ to $L$ ratio that is too high tend to perform worse than samples with normal gluten strength.
In this study, the two kinds of semolina were well separated with respect to the second axes (Figure 2), regardless of the addition of whey protein. Relaxation time $\tau_{i}$, which dominated PC2, clearly distinguished the $4 \mathrm{~T}$ samples from the $48 \mathrm{~T}$ samples, indicating that the $48 \mathrm{~T}$ samples had a greater relaxation time than the $4 \mathrm{~T}$ samples. The relaxation times can be considered an indication of the relative rates of molecular motion in dissipating stress [25], so the higher the relaxation time, the lower the chain mobility. Lower relaxation times may explain the higher leavening volume in the $4 \mathrm{~T}$ samples compared with the $48 \mathrm{~T}$ samples at the lower concentrations of whey proteins (i.e., $\mathrm{A}$ at $5 \%$ and $10 \%$ and $\mathrm{B}$ at 5\%). Edwards et al. [25] discussed the role of the relaxation time in the baking performance of common and durum wheat. The authors found that dough with lower relaxation times had higher loaf volumes and hypothesized that the strength of the dough is correlated with the relative molecular mobility. In the abovementioned substitution rates, the volume of leavening was $\sim 20 \%$ greater in the $4 \mathrm{~T}$ samples than the homologous doughs made from the strong commercial $48 \mathrm{~T}$, and this is consistent with their $\tau_{i}$ values.

3.3. Effect of Whey Powders on the Secondary Structure of Gluten. FT-IR spectra of dough samples were collected and analyzed to investigate the molecular differences among samples. Results are reported in Table 4. FT-IR spectra of $4 \mathrm{TC}$ and $48 \mathrm{TC}$ dough in the range of $1780-1440 \mathrm{~cm}^{-1}$ were similar to those found in other studies [17, 26]. Amide I and amide II are the most important bands in the infrared spectrum of proteins. The most intense absorption band is amide I, which was centred at about $1660 \mathrm{~cm}^{-1}$ in this study, and is mainly derived from the $\mathrm{C}=\mathrm{O}$ stretching of the peptide group combined with $\mathrm{N}-\mathrm{H}$ bending. The amide 
TABLE 4: The effect of OWP on the secondary structure of gluten as revealed by FT-IR. Data are reported as percentages of total area of amide I protein.

\begin{tabular}{|c|c|c|c|c|}
\hline Samples & $\alpha$-Helix & Random coil & $\beta$-Sheet & $\beta$-Turn \\
\hline $4 \mathrm{TC}$ & $12.8^{\mathrm{b}}$ & $13.6^{\mathrm{g}}$ & $51.7^{\mathrm{bc}}$ & $21.9^{\mathrm{b}}$ \\
\hline 4TA5 & $11.4^{\mathrm{b}}$ & $15.6^{\mathrm{de}}$ & $53.7^{\mathrm{b}}$ & $19.3^{\mathrm{bc}}$ \\
\hline 4TA10 & $11.3^{\mathrm{b}}$ & $14.0^{\mathrm{fg}}$ & $57.6^{\mathrm{a}}$ & $18.0^{\text {bd }}$ \\
\hline 4TA15 & $11.7^{\mathrm{b}}$ & $15.5^{\mathrm{de}}$ & $51.5^{\mathrm{bd}}$ & $21.8^{\mathrm{b}}$ \\
\hline 4TB5 & $12.7^{\mathrm{b}}$ & $14.1^{\mathrm{fg}}$ & $53.7^{\mathrm{b}}$ & $19.4^{\mathrm{bc}}$ \\
\hline $4 \mathrm{~TB} 10$ & $12.1^{\mathrm{b}}$ & $12.9^{g}$ & $53.7^{\mathrm{b}}$ & $21.1^{\mathrm{b}}$ \\
\hline $4 \mathrm{~TB} 15$ & $13.1^{\mathrm{b}}$ & $15.1^{\mathrm{ef}}$ & $51.8^{\mathrm{bc}}$ & $20.1^{\mathrm{bc}}$ \\
\hline $48 \mathrm{TC}$ & $13.6^{\mathrm{b}}$ & $11.5^{\mathrm{h}}$ & $48.9^{c e}$ & $25.9^{\mathrm{a}}$ \\
\hline 48TA5 & $16.0^{\mathrm{a}}$ & $16.7^{\mathrm{d}}$ & $47.8^{\mathrm{ef}}$ & $19.4^{\mathrm{bc}}$ \\
\hline 48TA10 & $16.5^{\mathrm{a}}$ & $18.5^{\mathrm{c}}$ & $46.7^{\mathrm{ef}}$ & $18.2^{\mathrm{bd}}$ \\
\hline 48TA15 & $17.0^{\mathrm{a}}$ & $19.9^{b c}$ & $48.0^{\mathrm{df}}$ & $15.1^{\mathrm{d}}$ \\
\hline $48 \mathrm{~TB} 5$ & $16.9^{\mathrm{a}}$ & $19.7^{\mathrm{bc}}$ & $48.3^{\mathrm{cf}}$ & $19.8^{\mathrm{bc}}$ \\
\hline $48 \mathrm{~TB} 10$ & $17.3^{\mathrm{a}}$ & $20.4^{\mathrm{ab}}$ & $45.2^{\mathrm{f}}$ & $17.2^{\mathrm{cd}}$ \\
\hline $48 \mathrm{~TB} 15$ & $17.8^{\mathrm{a}}$ & $21.3^{\mathrm{a}}$ & $44.7^{\mathrm{f}}$ & $17.1^{\mathrm{cd}}$ \\
\hline
\end{tabular}

Samples with different superscript letters within each column are significantly different at $p<0.05$ according to Duncan's multiple range test.

II band was found in the range of $1580-1510 \mathrm{~cm}^{-1}$; this band is more complex to study because it is derived from a combination of $\mathrm{N}-\mathrm{H}$ bending, C-N, and $\mathrm{C}-\mathrm{C}$ stretching. This is the reason why only the amide I band was studied in depth. The peak assignments to protein conformations in the amide I region were the same as reported by Wang et al. [18]: the bands located at $1650-1660 \mathrm{~cm}^{-1}$ were assigned to the $\alpha$-helix, the bands located at $1618-1640 \mathrm{~cm}^{-1}$ and $1670-1690 \mathrm{~cm}^{-1}$ were assigned to the $\beta$-sheet, the bands at $1660-1670 \mathrm{~cm}^{-1}$ and $1690-1700 \mathrm{~cm}^{-1}$ were assigned to $\beta-$ turns, and the band at $1645 \mathrm{~cm}^{-1}$ was assigned to random coils. The results of the curve fitting procedure (Table 4) show that the predominant secondary structure in the dough was the $\beta$-sheet conformation (about $50 \%$ ), as found by other authors [18], followed by $\beta$-turn and $\alpha$-helix and random coil conformation. We noted a clear separation between the two samples, $4 \mathrm{~T}$ and $48 \mathrm{~T}$, as far as the secondary structure of protein is concerned. In fact, in the $4 \mathrm{~T}$ samples the percentage of $\beta$-sheet structures was generally higher that the $48 \mathrm{~T}$ samples, and the percentage of $\alpha$-helix and random coil structures was lower. The $\beta$-sheet structures are indicative of protein aggregation $[17,27]$, and the increase of $\beta$-sheet and $\beta$-turn structures is an indicator of dough strength [18]. These data can offer a key to understand the differences in the volume of leavening between the two samples. In fact, as mentioned before, generally the $4 \mathrm{~T}$ samples showed a higher value of leavening volume than $48 \mathrm{~T}$, consistent with their higher content of $\beta$-sheet, and lower content of $\alpha$-helix and random coil structures. Secondary structures were highly sensitive to the addition of ovine whey powder in the $48 \mathrm{~T}$ semolina, where there was a significant increase in the $\alpha$-helix and random coil structures and a concomitant decrease of the $\beta$-turn structures, after the addition of whey powder. We suggest that a technological parameter may have influenced the relative percentage of the secondary structures. The $48 \mathrm{~T}$ samples differed from the $4 \mathrm{~T}$ samples with regard to mixing time (Table 3 ). It is worth noting that the mixing time was significantly higher in the $48 \mathrm{~T}$ samples compared with their homologous $4 \mathrm{~T}$ samples at each percentage of whey powder (Table 3); furthermore the mixing time increased as the amount of OWP increased. The longer mixing time may have been responsible for the disruption of the protein aggregates in the gluten network, as reported by other authors [28, 29], thereby explaining the decrease of the leavening volume in the $48 \mathrm{~T}$ samples upon OWP addition. This was reflected by the increase in random coil and unordered structures, which increased from $12 \%$ in the control $48 \mathrm{TC}$ sample to $20 \%$ in the $48 \mathrm{TA} 15(+66 \%)$ sample. Notably, the content of $\beta$-turn structures, which are highly dependent on the mechanical history of the sample $[30,31]$, decreased from $26 \%$ in the 48 TC sample to $19 \%$ in the 48 TA5 sample, whereas it remained unchanged in the $4 \mathrm{~T}$ samples.

\section{Conclusions}

In conclusion, the addition of OWP to semolina had a negative effect on the leavening volume of the dough, except when the OWP A was added at the lowest percentage (5\%), which means the lowest addition of whey proteins. In this study, the reduction of leavening volume in dough obtained with two types of semolina, supplemented with OWP, probably occurred because it led to a strong increase in dough elasticity and tenacity, in all samples. In the $48 \mathrm{~T}$ samples a longer mixing time was needed to reach the sought after consistency on the consistograph, than the $4 \mathrm{~T}$, and this was reflected in the higher content of unordered protein structures and lower content of $\beta$-sheets in the $48 \mathrm{~T}$ samples than $4 \mathrm{~T}$, as revealed by FT-IR spectra of the doughs. This suggested that the prolonged mixing caused partial disruption of the continuous gluten network. 


\section{Disclosure}

This article does not contain any studies with human or animal subjects.

\section{Conflicts of Interest}

The authors have no conflicts of interest to declare.

\section{Acknowledgments}

The work was carried out with the financial support of Sardegna Ricerche (TOP-DOWN program), project title "SIOPROFO."

\section{References}

[1] C. Fadda, E. M. Santos, A. Piga, and C. Collar, "Innovative traditional Italian durum wheat breads: Influence of yeast and gluten on performance of sourdough Moddizzosu breads," Cereal Chemistry, vol. 87, no. 3, pp. 204-213, 2010.

[2] V. Giannone, M. Giarnetti, A. Spina et al., "Physico-chemical properties and sensory profile of durum wheat Dittaino PDO (Protected Designation of Origin) bread and quality of remilled semolina used for its production," Food Chemistry, vol. 241, no. 2, pp. 242-249, 2017.

[3] H. D. Sapirstein, P. David, K. R. Preston, and J. E. Dexter, "Durum wheat breadmaking quality: Effects of gluten strength, protein composition, semolina particle size and fermentation time," Journal of Cereal Science, vol. 45, no. 2, pp. 150-161, 2007.

[4] G. Gallo, M. Lo Bianco, R. Bognanni et al., "Durum wheat bread: old Sicilian varieties and improved ones," Journal of Agricultural Science and Technology, vol. 4, no. 4, pp. 10-17, 2010.

[5] “EXPO Milano 2015," http://wwwexpo2015org/.

[6] C. Fadda, A. Angioloni, A. Piga, and C. Collar, "Impact of sourdough, yeast and gluten on small and large deformation rheological profiles of durum wheat bread doughs," European Food Research and Technology, vol. 231, no. 3, pp. 431-440, 2010.

[7] T. Nicolai, M. Britten, and C. Schmitt, " $\beta$-Lactoglobulin and WPI aggregates: Formation, structure and applications," Food Hydrocolloids, vol. 25, no. 8, pp. 1945-1962, 2011.

[8] R. S. H. Lam and M. T. Nickerson, "The effect of $\mathrm{pH}$ and temperature pre-treatments on the physicochemical and emulsifying properties of whey protein isolate," LWT- Food Science and Technology, vol. 60, no. 1, pp. 427-434, 2015.

[9] S. Patel, "Functional food relevance of whey protein: a review of recent findings and scopes ahead," Journal of Functional Foods, vol. 19, pp. 308-319, 2015.

[10] S. Sansonetti, S. Curcio, V. Calabrò, and G. Iorio, "Optimization of ricotta cheese whey (RCW) fermentation by response surface methodology," Bioresource Technology, vol. 101, no. 23, pp. 91569162, 2010.

[11] N. Secchi, G. Stara, R. Anedda et al., "Effectiveness of sweet ovine whey powder in increasing the shelf life of Amaretti cookies," LWT- Food Science and Technology, vol. 44, no. 4, pp. 1073-1078, 2011.

[12] AACC, American Association of Cereal Chemists Approved Methods, St. Paul, MN, USA, 10th edition, 2000.

[13] M. Dubois, A. Dubat, and B. Launay, The AlveoConsistograph Handbook, AACC International, St Paul, MN, USA, 2nd edition, 2008.
[14] P. Vinci, S. Fois, E. Parente, T. Roggio, and P. Catzeddu, "A study on relationships between durum wheat semolina properties, technological mixing parameters and the properties of dough after mixing," International Journal of Food Science \& Technology, vol. 48, no. 12, pp. 2541-2550, 2013.

[15] H. Singh, A. Rockall, C. R. Martin, O. K. Chung, and G. L. Lookhart, "The analysis of stress relaxation data of some viscoelastic foods using a texture analyzer," Journal of Texture Studies, vol. 37, no. 4, pp. 383-392, 2006.

[16] M. Campus, M. F. Addis, R. Cappuccinelli et al., "Stress relaxation behaviour and structural changes of muscle tissues from Gilthead Sea Bream (Sparus aurata L.) following high pressure treatment," Journal of Food Engineering, vol. 96, no. 2, pp. 192-198, 2010.

[17] A. S. Sivam, D. Sun-Waterhouse, C. O. Perera, and G. I. N. Waterhouse, "Application of FT-IR and Raman spectroscopy for the study of biopolymers in breads fortified with fibre and polyphenols," Food Research International, vol. 50, no. 2, pp. 574-585, 2013.

[18] J. J. Wang, G. Liu, Y.-B. Huang et al., "Role of N-terminal domain of HMW $1 \mathrm{Dx} 5$ in the functional and structural properties of wheat dough," Food Chemistry, vol. 213, pp. 682-690, 2016.

[19] S. Fois, C. Fadda, R. Tonelli et al., "Effects of the fermentation process on gas-cell size two-dimensional distribution and rheological characteristics of durum-wheat-based doughs," Food Research International, vol. 49, no. 1, pp. 193-200, 2012.

[20] H. Wieser and R. Kieffer, "Correlations of the amount of gluten protein types to the technological properties of wheat flours determined on a micro-scale," Journal of Cereal Science, vol. 34, no. 1, pp. 19-27, 2001.

[21] S. Kenny, K. Wehrle, C. Stanton, and E. K. Arendt, "Incorporation of dairy ingredients into wheat bread: Effects on dough rheology and bread quality," European Food Research and Technology, vol. 210, no. 6, pp. 391-396, 2000.

[22] D. Indrani, P. Prabhasankar, J. Rajiv, and G. V. Rao, "Influence of whey protein concentrate on the rheological characteristics of dough, microstructure and quality of unleavened flat bread (parotta)," Food Research International, vol. 40, no. 10, pp. 12541260, 2007.

[23] A. B. Madenci and N. Bilgiçli, "Effect of Whey Protein Concentrate and Buttermilk Powders on Rheological Properties of Dough and Bread Quality," Journal of Food Quality, vol. 37, no. 2, pp. 117-124, 2014.

[24] N. Erdogdu-Arnoczky, Z. Czuchajowska, and Y. Pomeranz, "Functionality of whey and casein in fermentation and in breadbaking by fixed and optimized procedures," Cereal Chemistry, vol. 73, no. 3, pp. 309-316, 1996.

[25] N. M. Edwards, D. Peressini, J. E. Dexter, and S. J. Mulvaney, "Viscoelastic properties of durum wheat and common wheat dough of different strengths," Rheologica Acta, vol. 40, no. 2, pp. 142-153, 2001.

[26] D. M. R. Georget and P. S. Belton, "Effects of temperature and water content on the secondary structure of wheat gluten studied by FTIR spectroscopy," Biomacromolecules, vol. 7, no. 2, pp. 469-475, 2006.

[27] A. Ravi, C. Perera, S. Y. Quek, and D. Sun-Waterhouse, "Physico-chemical properties of bread dough fortified with fruit fibers and phenolic antioxidants," in Proceedings of the oral presentation at the 2009 Institute of Food Technologists (IFT) Annual Meeting \& Food Expo, Anaheim, CA, USA, 2009. 
[28] T. Aussenac, J.-L. Carceller, and D. Kleiber, "Changes in SDS solubility of glutenin polymers during dough mixing and resting," Cereal Chemistry, vol. 78, no. 1, pp. 39-45, 2001.

[29] H. D. Belitz, R. Kieffer, W. Seilmeier, and H. Wieser, "Structure and function of gluten proteins," Cereal Chemistry, vol. 63, pp. 336-341, 1986.

[30] N. Wellner, E. N. C. Mills, G. Brownsey et al., "Changes in protein secondary structure during gluten deformation studied by dynamic fourier transform infrared spectroscopy," Biomacromolecules, vol. 6, no. 1, pp. 255-261, 2005.

[31] N. Secchi, The ability of ovine whey powder to improve quality of Sardinian bakery products, [Ph.D. thesis], 2015/2016, http:// eprints.uniss.it/11649/1/Secchi_N_The_ability_of_ovine. 


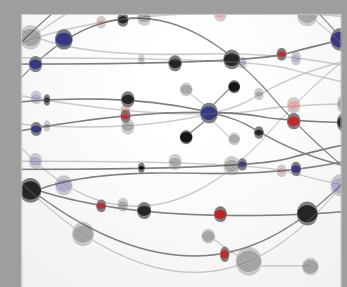

The Scientific World Journal
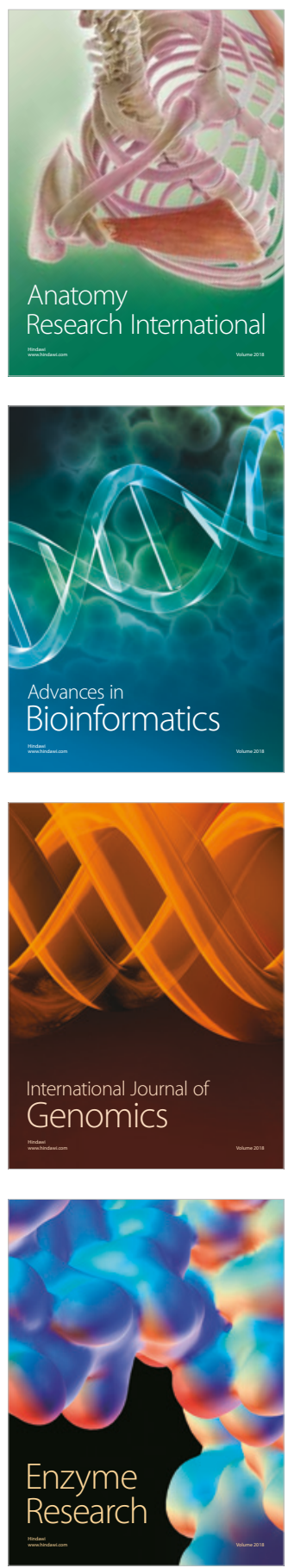
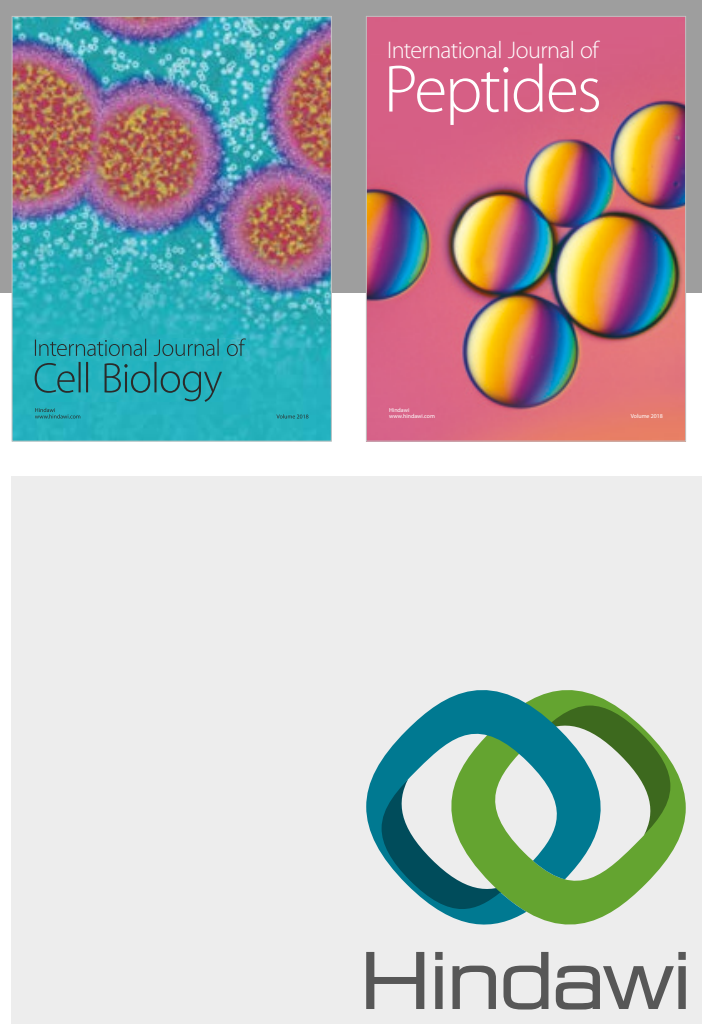

Submit your manuscripts at

www.hindawi.com
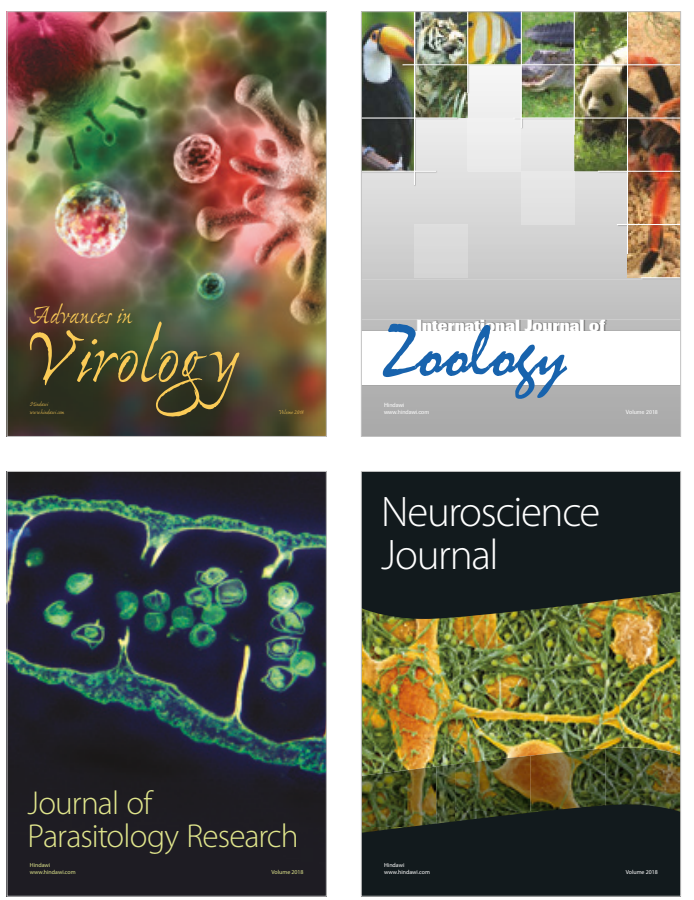
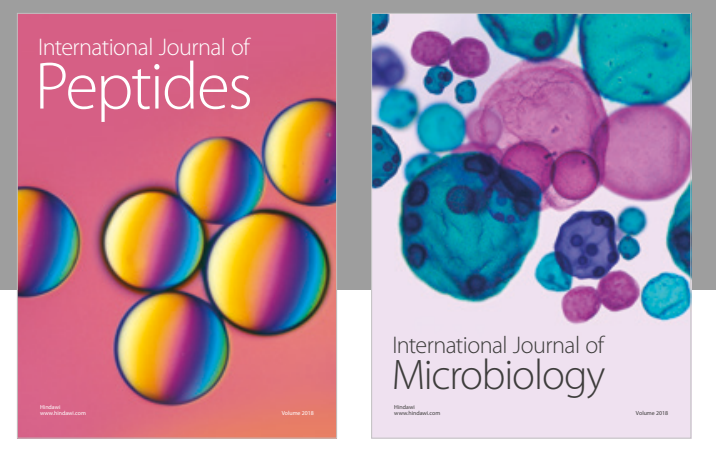

nternational Journal of Microbiology
Journal of
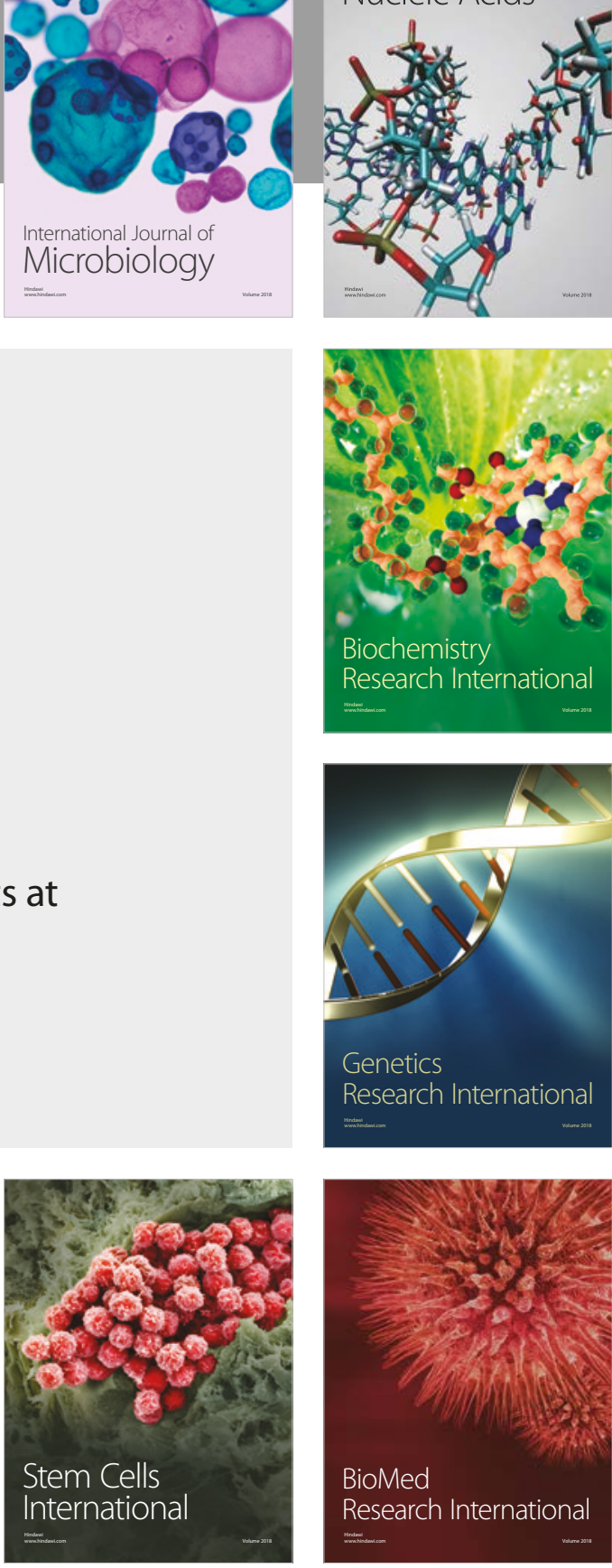
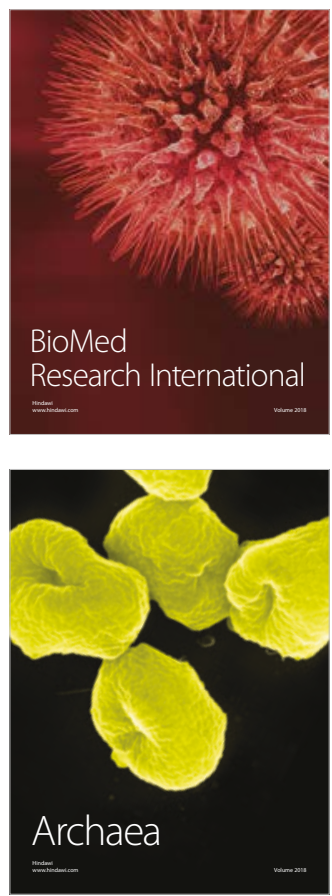